\title{
Inner Speech, Active Part of Working Memory Phonological Loop, Inactive in Dementia
}

\author{
Maryam Atabati ${ }^{1 *}$, Nader Jahangiri ${ }^{1}$, Naghmeh Mokhber ${ }^{2}$ \\ ${ }^{1}$ Department of Linguistics, Ferdowsi University of Mashhad, Mashhad, Iran; \\ ${ }^{2}$ Psychiatry and Behavioral Sciences Research Center of Mashhad University of \\ Medical Sciences, Mashhad, Iran. \\ Email: *Maryam.atabati@yahoo.com \\ Received June $1^{\text {st }}$, 2011; revised July 17 ${ }^{\text {th }}, 2011$; accepted August 26 $6^{\text {th }}, 2011$.
}

\begin{abstract}
This paper examines the role of inner speech in storage and retrieval of working memory phonological loop by conducting maintenance rehearsal test on eighteen elderly participants in two groups: a healthy group and a group with dementia. A Mann-Whitney U test was used to analyze the data. Through a comparison of the rehearsal manner of the two groups, it was concluded that the pattern of normal rehearsal of the healthy group was different from the pattern of patients suffering from dementia: also, the activity of working memory phonological loop in the healthy group was different from the lack of activity of working memory phonological loop in patients. That is, that subjects with dementia cannot use inner speech in the form of subvocal repetition was explained by applying the "Baddeley and Hitch" model of memory.
\end{abstract}

Keywords: Inner Speech, Maintenance Rehearsal, Phonological Loop, Dementia

\section{Introduction}

To memorize something, one should either establish semantic relationships between that thing and the experiences that exist in their mind and expand their mental connection network or commit it to memory by repetition. In all of these stages, language on its own is active. Whether when we are trying in finding the actual or artificial relation of new events with past events or when we embark on repeating to achieve mental maintenance, it seems that the role of language is examinable between childhood amnesia and old age amnesia. Because major cases of deficiency and weakness of memory forces are being manifested in old age and also because the rehearsal and self-directed speech are having the role of memory sign maintenance, the study of the nature of self-directed speech in old age in two groups of healthy subjects and patients could be illustrative of the difficulties related to the decline of verbal memory in old age. Because in "free recall" memory, mental processes have not been dealt with and only the output has been at the center of attention, the need for a close analysis of the processes going on with the subjects ranging from the representation of signs to recall was felt. Also, as the subjects attempt to remember the signs, the role of language in memory during the rehearsal condition of the subjects was revealed. The goal of this research is to create a strategy to determine the early lack of inner speech application in old age, that is, recognition of unnatural rehearsal can be a warning for memory dementia. Lack of sonic motion is probably the major reason why inner speech has not been sufficiently dealt with. Playing a memory-refreshing role, inner speech is a significant value to memory, which is subject to gradual process of senescence, especially a growing tendency among the elderly to use external mnemonic devices such as resorting to others for reminders or using notes to help remind things, which is indicative of inner mnemonic weakness. Therefore, showing the lack of effective utilization of self-directed speech as an inner mnemonic can more closely explain the role of this language in deficiency of old age memory and can help the therapy of patients with dementia. It also can prevent occurrence of dementia by keeping inner speech and private speech active. Because learning things opens direction in memory and review of them stabilizes this direction and when we use to combine schemata, organization, and elaboration, these directions join together, and thus, the memory ability will develop.

\section{Multi-component Working Memory}

Baddeley and colleagues (Baddeley, 1992; Baddeley \& Hitch, 1974; Baddeley and Logie, 1999) developed a multicomponent working memory in which we can see two major storage systems including visuo-spatial sketchpad and the phonological loop. One central executive system coordinates two storage systems. The phonological loop holds speech-based information that is the acoustic and phonological properties of words, letters, and numbers together. The phonological loop has been fractionated into a passive phonological store and the active articulatory subvocal rehearsal process, inner speech. (Logie, 2003, p41) that refreshes traces of memory. The visuospatial sketchpad deals with visual information. This system has been fractionated into a passive visual cache and an active spatial inner scribe (Logie, 1995). The episodic buffer is able to combine different information from phonological loop and visuo-spatial working memory into a single representation (Baddeley, 2000, 417-423).

\section{Methods}

Because reading ability of monosyllabic words is remained in many of the patients with dementia, overt maintenance rehearsal test can be done in these cases. In advanced cases of illness, the patient is not able to distinguish some of the letters of the word being read. However, this matter is not seen in all the patients: some patients gradually lose their reading ability 
and letter distinction. In showing the importance of self-directed speech and its role on verbal memory, we should follow up the way in which we can measure language in the maintenance of mental health. Therefore, we designed and performed maintenance rehearsal test to compare the rehearsal pattern of healthy subjects and patients: from this comparison, we found out the differences of rehearsal in them. Ability, rapid repetition, and congestion rehearsal are assessed in this way. In old age, decreased reading ability is possible, and sentence writing may be impossible or hard with tremor or hand deficiency. Cases of hearing weakness that causes individuals to become unsuccessful in their interview response to the Mini-Mental State Examination have been regarded in subject selection.

\section{Participants}

A total of 18 participants were examined; 9 persons were healthy, and 9 persons were affected by amnesia. Participants ranged in age from $60-85$ years (mean age $72.27 \mathrm{yrs}$ ), s.d = 8.29 and composed of 14 men and 4 women. The MMSE score for the controls with apparently normal cognition was higher than 25 , and that for patients with amnesia was $0-18$.

\section{Tasks}

Maintenance Rehearsal Test.

This study is based on overt rehearsal that follows up the congestion rehearsal patterns. We used monosyllabic words with frequency values between 10 and 50 per million and familiarity values of 100 . These words were selected from MCR Psycholinguistics Data Base related to other reports (Wilson 1988), and in the translation of ideal words to Persian with consideration of semantic limits, word lists were one composed of 24 practice cards and 16 original cards with insertion of word on every card, which was fixed for all the subjects and examined separately. Practice lists for the subjects were in the form of 2 test lists composed of 12 cards. First, the practice cards were presented for all the participants, and they vocalized words on the cards. During this time, thery were guided on how they would proceed. Then, the participants were given the opportunity to prevent the interference between the rehearsal of the original list and the practice list because some words in the practice list might have remained in the long-term memory (LTM). The time was variable for the controls and the patients with amnesia. Then, the original list was presented for $1 \mathrm{sec}$, and the participants had a mean gap of $6 \mathrm{sec}$ for vocalizing the new words and overt rehearsal of all the words from the first. The participants were guided continually. This was the manner of giving possible active rehearsal to the participants.

\section{Results and Discussion}

\section{Comparison of the Whole Word Repetitions in Two Groups (Figure 1)}

The Mann-whitney $U$ test was used to analyze the difference in the number of whole word repetition in all 16 positions between the two groups. The results show that the number of whole word repetition in the controls (first group) is significantly more than that of the patients (second group). Box diagram consists of five sections: minimum of data, maximum of data, mean, first quarter, and third quarter. Minimum of data shows the group down level, maximum of data shows the group upper level, first quarter includes $25 \%$, and third quarter includes $75 \%$ of data in every group. This box diagram shows that $25 \%$ of the controls had whole word repetitions of approximately 78 , and $50 \%$ of them had 80 repetitions. Also, the repetitions of the $75 \%$ of them was more than the mean. In the first qroups, the outlying data show that the individual whole word repetitions had a difference with the mean of the whole group word repetitions. The mean of whole repetitions for the controls was 83.22 , and that for the patients was 36.56 . Because the P-value of this test is $\alpha=0.05$, then the difference between the two groups is significant. Therefore, in the following, we consider these three-word repetitions in the two groups.

\section{Comparison of the Whole Word Repetition in all the 16 Positions in the Two Groups (Figure 2)}

To compare the whole number of every word repetition in all the 16 positions, the Mann-whitney $U$ test was used. The results show that primacy effect exists only in controls. This effect is the movement of primary words toward the end of the list through rehearsal. The primacy effect continues until the seventh word in the rehearsal of the controls, but this effect is significant until the third word. In general, the first, second, and third words have been repeated in the controls more than the group with dementia.

The control group, with a mean of 24.22 , has repeated the first word in all of its 16 positions more than the patient group with a mean of 3.89 . Because $\alpha=0.000<0.05$, then the difference of the first word repetition between the two groups is significant.

The control group, with a mean of 17.44 , has repeated the second word in all of its 16 positions more than the patient group with a mean of 2.78 . Because $\alpha=0.001<0.05$, then the difference of second word repetition between two groups is significant.

The control group, with a mean of 5.78, has repeated the third

P-value $=0.001$

\begin{tabular}{lccccc}
\hline \multicolumn{5}{c}{ Group Statistics } \\
\hline Group & $\mathrm{N}$ & Mean & $\begin{array}{c}\text { Std. } \\
\text { Deviation }\end{array}$ & $\begin{array}{c}\text { Std. } \\
\text { Error Mean }\end{array}$ \\
\hline Total & 1 & 9 & 83.22 & 24.035 & 8.012 \\
& 2 & 9 & 36.56 & 26.097 & 8.699 \\
\hline
\end{tabular}

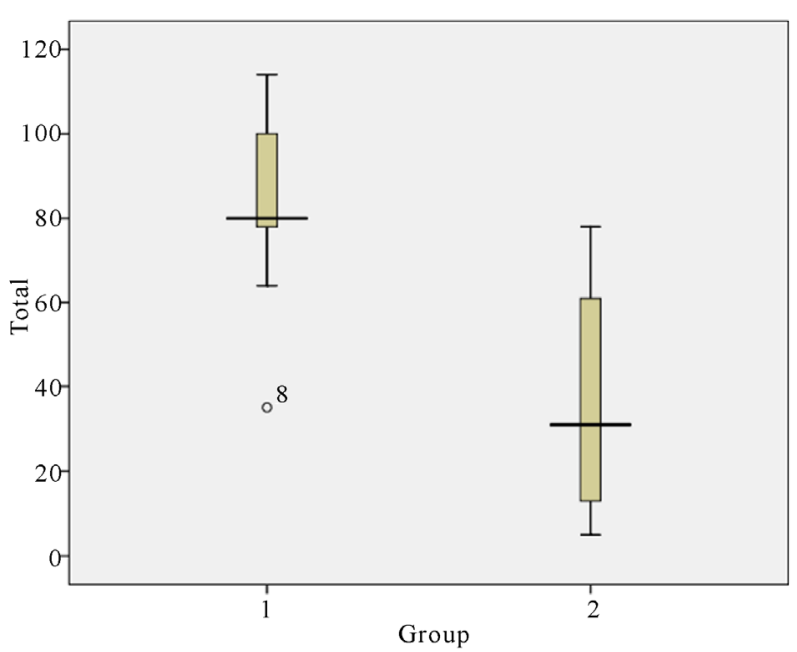

Figure 1.

Comparison of the whole word repetition in the two groups. 


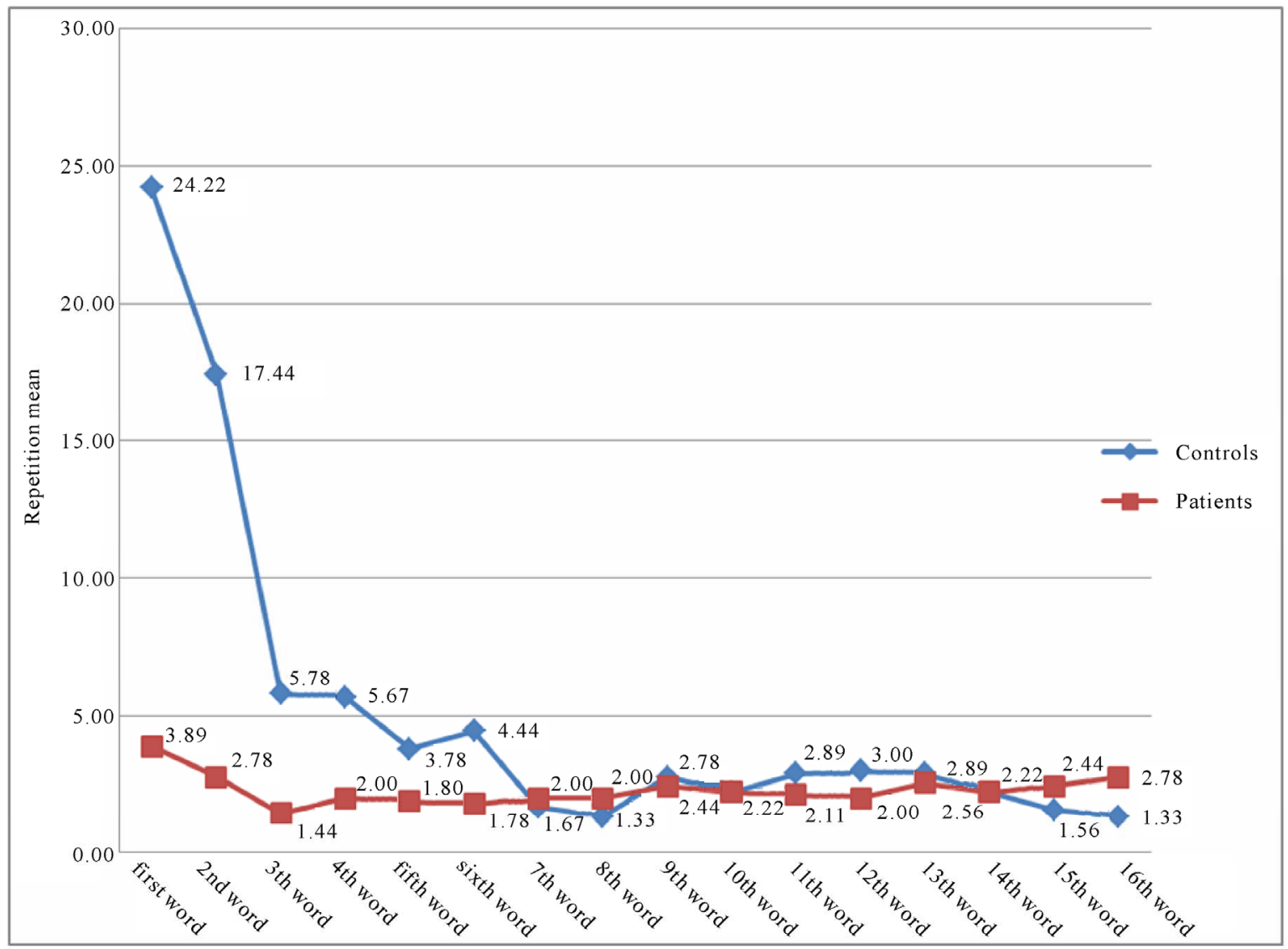

Figure 2 .

The mean of every word repetition in all the 16 positions.

$1-$ First word $(\mathrm{P}$-value $=0.000)($ Figure 3$)$

\begin{tabular}{lccccc}
\hline \multicolumn{6}{c}{ Group Statistics } \\
\hline & Group & N & Mean & $\begin{array}{c}\text { Std. } \\
\text { Deviation }\end{array}$ & $\begin{array}{c}\text { Std. } \\
\text { Error Mean }\end{array}$ \\
\hline First_Word_Total & 1 & 9 & 24.22 & 9.922 & 3.307 \\
& 2 & 9 & 3.89 & 4.512 & 1.504 \\
\hline
\end{tabular}

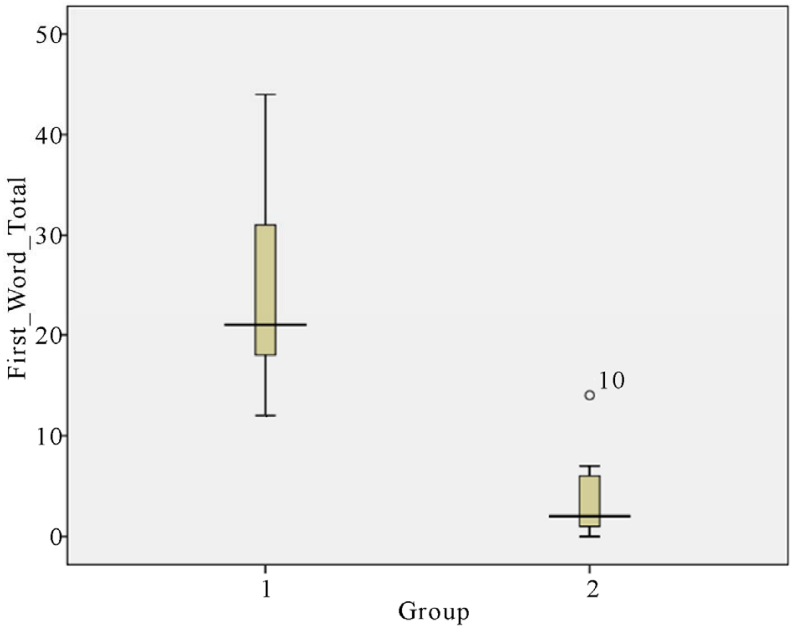

Figure 3 .

Comparison of the first word repetitions in the two groups: (1-control and 2-patients).
2-Second word $(\mathrm{P}$-value $=0.001)($ Figure 4$)$

\begin{tabular}{ccccc}
\hline \multicolumn{5}{c}{ Group Statistics } \\
\hline Group & $\mathrm{N}$ & Mean & $\begin{array}{c}\text { Std. } \\
\text { Deviation }\end{array}$ & $\begin{array}{c}\text { Std. } \\
\text { Error Mean }\end{array}$ \\
\hline 1 & 9 & 17.44 & 7.699 & 2.566
\end{tabular}

W2_Total

$\begin{array}{lllll}2 & 9 & 2.78 & 2.333 & .778\end{array}$

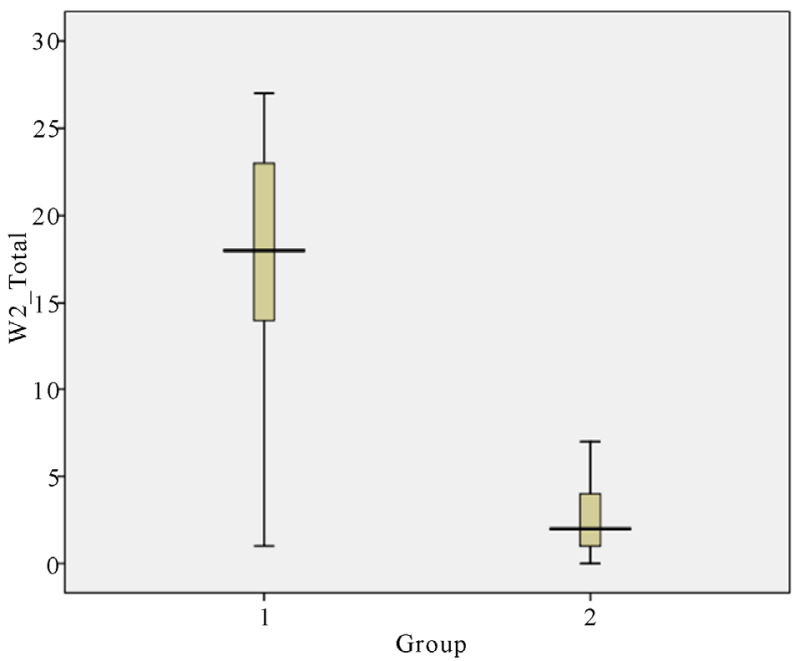

Figure 4.

Comparison of second word repetitions in the two groups. 
3-Third word $(\mathrm{P}-\mathrm{value}=0.014)($ Figure 5)

\begin{tabular}{cccccc}
\hline \multicolumn{6}{c}{ Group Statistics } \\
\hline Group & $\mathrm{N}$ & Mean & $\begin{array}{c}\text { Std. } \\
\text { Deviation }\end{array}$ & $\begin{array}{c}\text { Std. } \\
\text { Error Mean }\end{array}$ \\
\hline W3_Total & 1 & 9 & 5.78 & 5.069 & 1.690 \\
& 2 & 9 & 1.44 & 1.740 & .580 \\
\hline
\end{tabular}

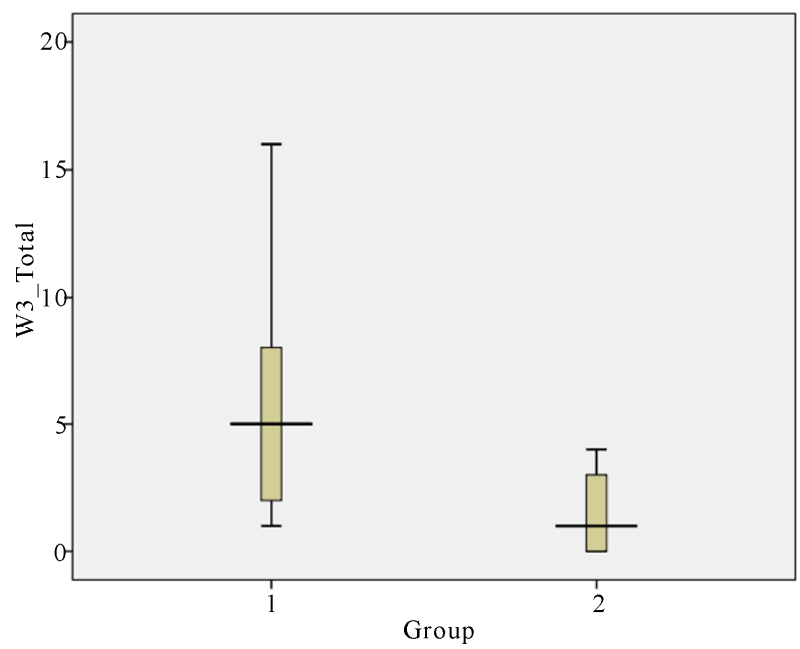

Figure 5.

Comparison of third word repetitions in the two groups. word in all its 16 positions more than the patient group with a mean of 1.44 . Because $\alpha=0.014<0.05$, then difference of third word repetition between the two groups is significant.

\section{The Mean of Word Repetitions in Each Position for the Two Groups (Figure 6)}

The Mann-Whitney $U$ test was used to compare the word repetition number in every position. The results indicate that there is no significant difference between the two groups in the three positions: first, eleventh, and sixteenth: however, in other positions, the controls had more whole number of word repetition significantly in every position than the second group.

\section{The Mean of Retrieved Words per 15 Positions (Figure 7)}

The results show that in all of 15 positions (except the first position), the controls recalled the more word number than the second group.

According to Brown et al, any general retrieval deficit could lead to impaired rehearsal and to a selective impairment of primacy (Brown et al, 2007, p257).

\section{The Percentage of Word Repetitions Belonging to Previous Words (Figure 8)}

To compare the percentage of previous word repetition ability, the Mann-Whitney $U$ test was used. The results show that the controls have repeated previous words significantly more than the second group $(\mathrm{P}$-value $=0.000)$.

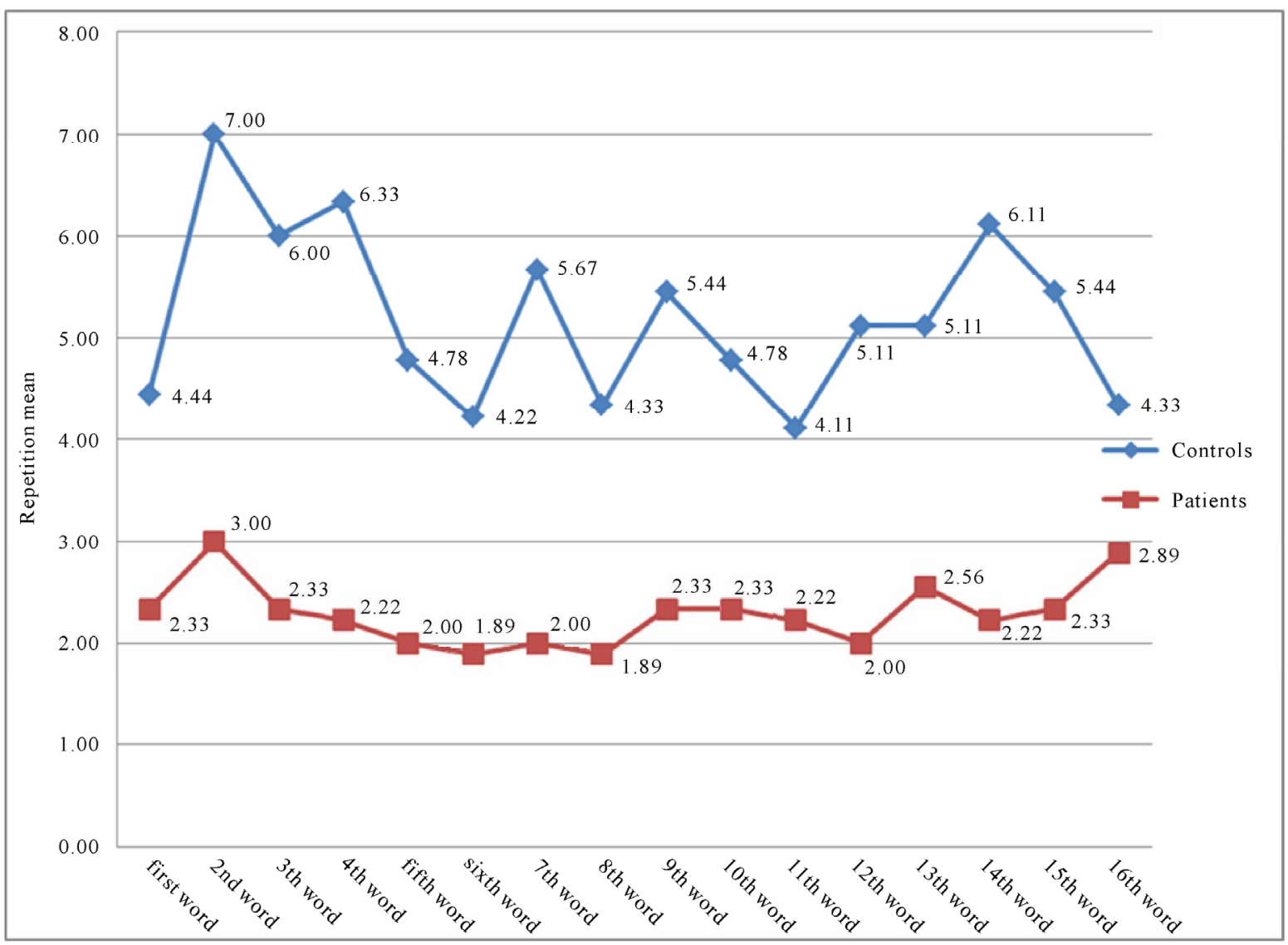

Figure 6.

Word repetitions in each position for two groups. 


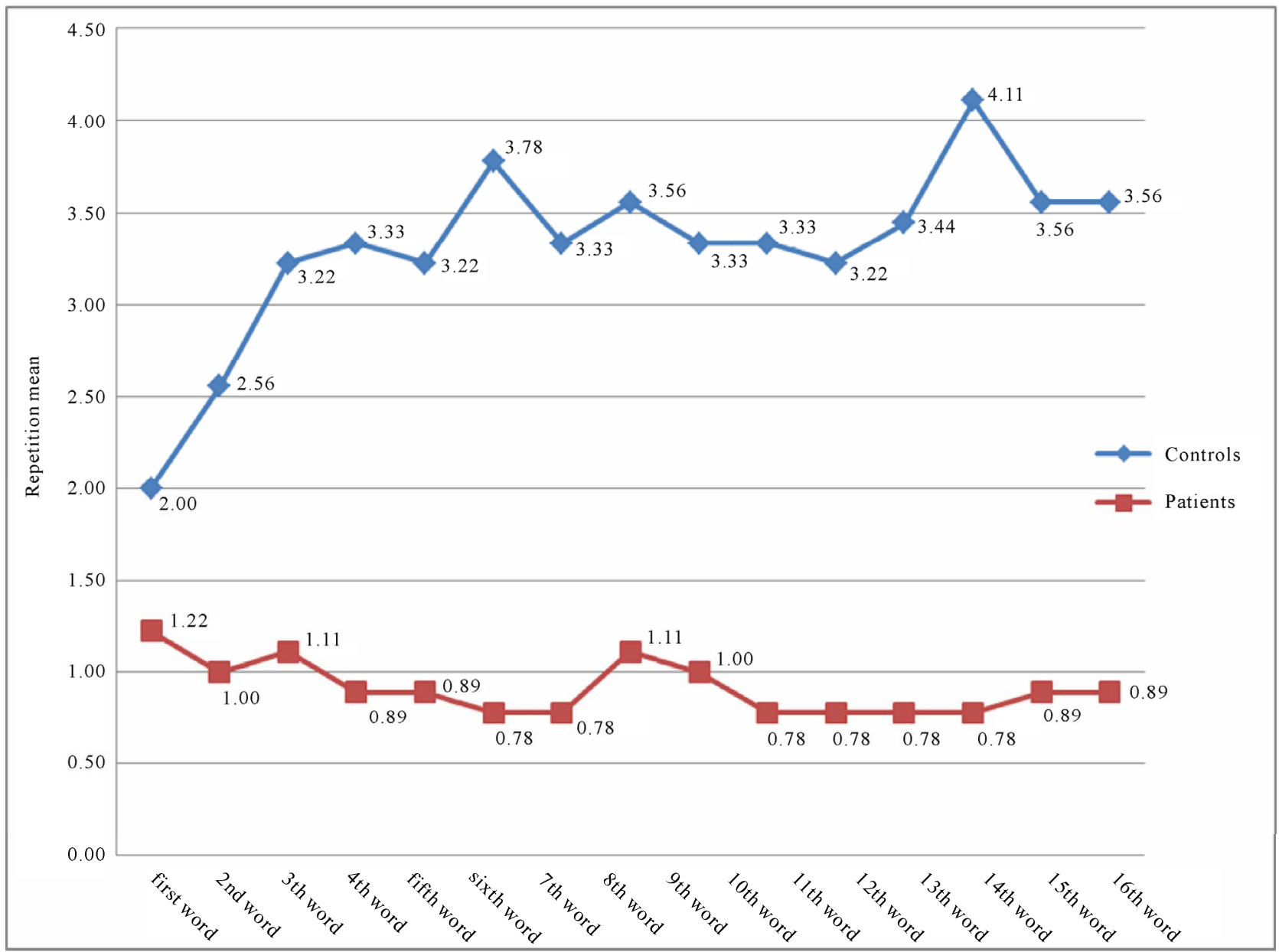

Figure 7.

The percentage of repetitions belonging to previous words.

\begin{tabular}{cccccc}
\hline & Group & N & Mean & $\begin{array}{c}\text { Std. } \\
\text { Deviation }\end{array}$ & $\begin{array}{c}\text { Std. } \\
\text { Error Mean }\end{array}$ \\
\hline $\begin{array}{c}\text { Percent of } \\
\text { Previous Words }\end{array}$ & 1 & 9 & .6122 & .15398 & .05133 \\
\hline
\end{tabular}

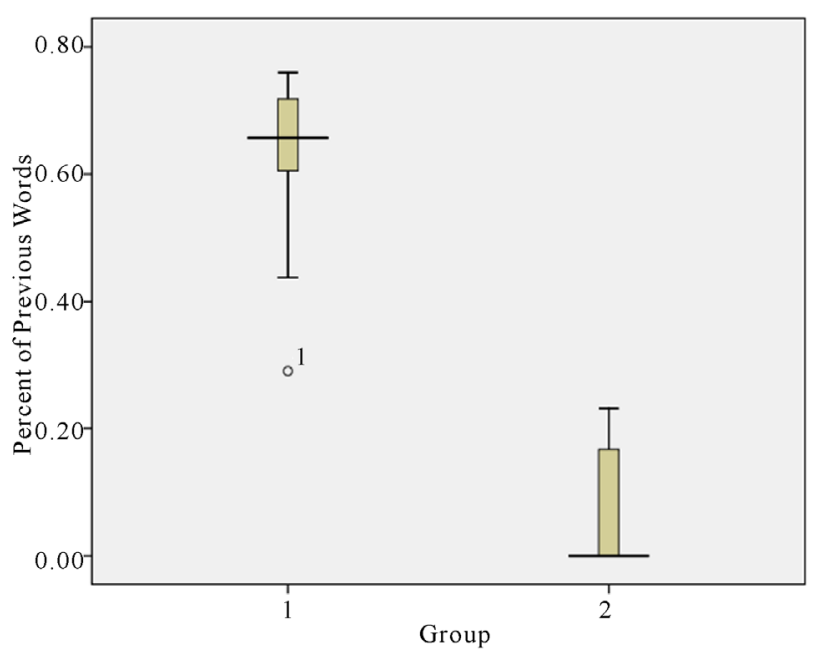

Figure 8.

The percentage of word repetitions belonging to previous words.
Approximately $61 \%$ of words repeated by the controls be long to those of previous positions, and only $7 \%$ of words were repeated by the patients.

It case shows within-list retrieval of two groups. There is an individual whole previous word repetition of $43 \%$ in minimum and an individual whole previous word repetition of $80 \%$ in maximum in the control group. Also, there are outlying data among the controls with whole previous word repetition of $30 \%$.

\section{Analysis of Maintenance Rehearsal Test Result in the Working Memory Model (Figure 9)}

The shape of the phonological short-term memory process of Baddeley et al. (1984) cited in Jacquemot and Scott (2006, p 481) shows two separated entrances of visual and auditory inputs to the working memory (Baddeley, 1992; Baddeley \& Hitch, 1974; Baddeley and Logie, 1999). According to this model, the auditorily presented material enters the phonological store automatically, and the visually presented material must be articulated before it can enter the phonological store (Hanley, 1997, p 429).

In this study the patients have had $7 \%$ within-list retrieval and the controls $61 \%$ within-list retrieval. Then the controls have done necessary repetition for transferring of visual inputs to their working memory phonological loop but the patients have not done. We have presented to participants the lingual 


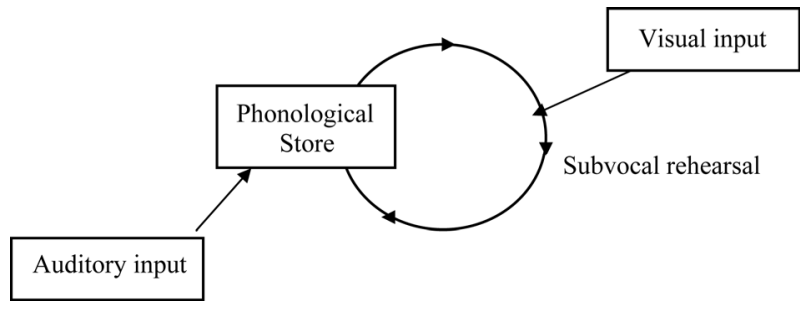

Figure 9.

Jacquemot \& Scott, 2006, p 481.

visual inputs therefore, the inputs can not access to phonological store unless the participants can read and repeat them. 7\% within-list retrieval of patient group in overt rehearsal test suggests that their vocal rehearsal process is weak. Also, it implys that their articulatory subvocal rehearsal process is inactive too. Use of the overt rehearsal procedure does not change the basic effects observed in free recall (Tan \& Ward, 2000, cited in Brown et al, 2007, p257).

Therefore, when there is deficiency of articulatory rehearsal, the possibility of memory traces vita will lose a few seconds after the relevant word representation. Verbal language, that is, auditory input, and writing language, that is, visual input, interact with the working memory phonological loop. This storage system includes two articulatory rehearsals and maintenance of speech-based information. When an individual sees and vocalizes pertinent word, and if the rehearsal part in the memory phonological loop is active, this word will remain in the maintenance part of this store. Repeating the word after seeing and vocalizing, whether mentally or overt, is the reason that word remains in the working memory phonological loop. Every repetition itself is a lingual input; this auditory input enters the working memory phonological loop and the inner speech by means of continuous repetition, termed "maintenance rehearsal," protects that input in the memory. Then, the inner speech role is to create a rehearsal state for maintaining the memory phonological loop inputs. In this respect, rehearsal can maintain only phonological representation, whereas refreshing can maintain any representations through focus of attention. Both of them aid in the maintenance of verbal information (Camos et al., 2010). Participants were encouraged to apply the cumulative rehearsal and there was no phonological similarity within our list. Therefore all of the participants just operated like the instruction. However, overt rehearsal should have the necessary speed. Low speed of speech provides less rehearsal in a limited time. Therefore, it provides fewer subsequent inputs in patients than in healthy people. If we carry out this rehearsal with a period of approximately $6 \mathrm{sec}$ for gaps between the representations in experimental conditions, we can find within-list retrievals from the repetition ability and its subsequent, creating latter inputs for the working memory phonological loop, which they indicate as active rehearsal in the verbal memory. We consider a human memory span limitation of $7 \pm 2$. Despite the representation of 16 words which can be affected by the preference of the participants. The other researchers tested articulatory suppression effect on phonological loop in healthy people. They tried to suppress rehearsal. Salame and Baddeley (1982) claimed that articulatory suppression reduced overall levels of serial recall because the items were unable to gain access to the phonological store (Hanley, 1997, p424). Suppression during visual input impedes rehearsal by occupying the rehearsal loop (Toppino \& Pisega, 2005, p375).

They suppressed rehearsal in healty people, but our findings suggest that rehearsal decreses in dementia per se. The results are the same, reduction of recall. On the other hand, the primacy effect reflects the use of rehearsal to carry forward early-list item selectively (Tan \& Ward, 2000, cited in Brown et al, 2007, p259). And the controls had such primacy effect until the seventh word, but the patients had not. Through a comparison of the rehearsal manner of the two groups, impaired primacy effect in group with dementia, it is concluded that the pattern of overt rehearsal of the healthy group is different from the pattern of patients suffering from dementia (Figures 2 and 6). Brown et al. (2007) reported classic amnesic pattern of substantially impaired primacy about one anterograde amnesiac patient.

\section{Conclusions}

Subvocal rehearsal is the state of inner speech utilization, which exists in normal older people, and we present it in experimental conditions. The passive rehearsal pattern is seen in older people with dementia, who are not able to repeat stimulus effectively and use inner speech. Thus, the rehearsal patterns of the controls and the patients are different.

There are no primacy effects in the group with dementia, and there are various repetition loses. In other words, the percentage of the number of repetition belonging to previous words declines, and the mean number of retrieved words per 15 positions included in the within-list retrievals significantly decreases. There is inner speech in the form of subvocal repetition in normal old age individuals, and it is responsible for converting and maintenance of visual input to verbal silent input by rehearsal. Therefore, the inner speech in the form of subvocal repetition is a storage system, and also, it is possible that private speech can be charged for the transition of visual input to retrieval part of the phonological loop. Then, we deal with whisper or more audible speech which can keep visual inputs in memory phonological loop in the verbal repetition condition. Then, private speech in the form of vocal repetition is a storage system. Thus, deficiencies of inner speech and private speech storage system will lesson the possibility of retrievals from the phonological loop in older people affected by dementia.

\section{References}

Baddeley, A. D., \& Hitch, G. J. (1974). Working memory. In G. H. Bower (Ed.), The Psychology of Learning and Motivation, Vol. 8. London: Academic Press.

Baddeley, A. D. (2000). The episodic buffer: A new component of working memory? Trends in Cognitive Science, 4, 417-423. doi:10.1016/S1364-6613(00)01538-2

Baddeley, A. (2003). Working memory: Looking back and looking forward. Nature Reviews Neuroscience, 4, 829-839. doi:10.1038/nrn1201

Baddeley, A. D., \& Dlarsen, J. (2007). The phonological loop: Some answers and some questions. The Quarterly Journal of Experimental Psychology, 60, 512-518. doi:10.1080/17470210601147663

Brown, D. A. G. (2007). Brief reports amnesia, rehearsal and temporal distinctiveness models of recall. 256-260.

http://pbr.psychonomic-journals:content /14/2/256.abstract

Hanley, R. (1997). Does articulatory suppression remove the irrelevant speech effect? Psychology Press Memory, 5, 423-431.

Logie, R. H. (2003). Spatial and visual working memory-a mental workspace. Elsevier Science, 41-42.

Jacquemot, C., \& Scott, K. S. (2006). What is the relation between phonological short-term memory and speech processing? http://www.sciencedirect.com, vol.10, 480-481. 
Wilson, M. (1988). MCR psycholinguistics database: Machine usable dictionary, Version 2.00. behavior research methods.

Toppino, T., \& Pisegna, A. (2005). Articulatory suppression and the irrelevant speech effect in short- term memory: Does the locus of suppression matter? Psychonomic Bulletin \& Review, 12, 374- 379.
doi:10.3758/BF03196387

Camos, V., Mora, G., \& Oberauer, K. (2010). Adaptive choice between articulatory rehearsal and attentional refreshing in verbal working memory. The Psychonomic Society, Springer. 